\title{
Acute coronary syndrome in a young lady: a rare presentation of takayasu disease
}

\begin{abstract}
Acute coronary syndromes mainly affect patients with cardiovascular risk factors, it may occur in non-atherosclerotic patients such those with systemic disease. Coronary artery involvement occurs in $10 \%$ to $30 \%$ of cases of Takayasu arteritis. The present report describes the case of a young woman presented for a myocardial infarction revealing a Takayasu disease

A 30-year-old woman, with no medical history, was admitted to the emergency department with a clinical picture of acute coronary syndrome, with a significant asymmetry in pulses and blood pressure between right and left limb. The diagnosis of non ST elevation myocardial infarction was made. Coronary angiography revealed a severe stenosis of the left main coronary artery. Transthoracic echocardiography showed an impaired left systolic function, regional wall-motion abnormalities. Laboratory tests showed an elevation of inflammatory parameters. Results for syphilis and HIV were negative. Immunological markers were negative. Takayasu disease has been retained on ACR criteria. Our patient has experienced a heart arrest and was resuscitated. Coronary artery bypass surgery was performed. In addition to classical treatment of myocardial infarction, immunosuppressive therapy was established. A second acute coronary syndrome has occurred; percutaneous coronary angioplasty of the left main coronary artery was performed with implantation of a drug-eluting stent.

Large-vessel vasculitis with a coronary involvement can result in a myocardia infarction. Coronary involvement is rare in Takayasu disease but not exceptional. It should be considered in young women with no medical history, presenting with myocardial infarction.
\end{abstract}

Keywords: acute coronary syndrome, takayasu, arteritis, angiography, coronary syndrome, hypertension
Volume 6 Issue 3 - 2017

\author{
Abire Allaoui \\ Department of Internal Medicine, Ibn Rochd University \\ Hospital, Morocco
}

Correspondence: Abire Allaoui, Department of Internal Medicine, FMPC-University Hassan II, Ibn Rochd University Hospital, Morocco, Email abire.allaoui@gmail.com

Received: March 01, 2017 | Published: March 06, 2017

\section{Resume}

Les syndromes coronariens aigus atteignent habituellement des patients avec des facteurs de risque cardiovasculaires, mais ils peuvent survenir chez des patients sans athérosclérose avec une maladie systémique. L'atteinte coronarienne survient dans $10 \%$ à $30 \%$ des cas dans une maladie de Takayasu. Cette observation décrit le cas d'une jeune femme ayant présenté un infarctus du myocarde ayant révélé le Takayasu.

Une patiente de 30 ans sans antécédents médicaux, s'est présentée aux urgences avec un tableau clinique de syndrome coronarien aigu. L'examen notait une asymétrie des pouls et de la tension artérielle. Un syndrome coronarien ST- a été diagnostiqué. La coronarographie montrait une sténose sévère de la coronaire gauche. L'échocoeur notait une dysfonction du ventricule gauche et des anomalies de la contractilité régionale. La biologie montrait un syndrome inflammatoire. Les sérologies étaient négatives pour la syphilis et le VIH. Le bilan immunologique était négatif. Le diagnostic du Takayasu a été retenu selon les critères ACR. Notre patiente a présenté un arrêt cardiaque et a été réanimée. Un pontage coronarien a été placé. En plus du traitement médical classique de l'infarctus du myocarde, une immunosuppression a été entreprise. Un deuxième syndrome coronarien est survenu, une angioplastie percutanée de la coronaire gauche et un stent actif ont été mis en place.

Les vascularites des gros vaisseaux avec une atteinte coronarienne peuvent se présenter par un infarctus myocardique. L'atteinte coronarienne est rare mais pas exceptionnelle lors du Takayasu. Ce diagnostic doit être considéré devant une jeune femme sans antécédents présentant un infarctus du myocarde.

\section{Motsclé}

Syndrome coronarien aigu, Maladie de Takayasu Coronary artery disease is a major public health problem in the world. Acute coronary syndromes mainly affect patients with cardiovascular risk factors, it may occur in non-atherosclerotic patients. Among these patients, systemic disease can affect coronary arteries. Coronary artery involvement occurs in $10 \%$ to $30 \%$ of cases of Takayasu arteritis (TA). The present report describes the case of a young woman presented for a myocardial infarction revealing a TA.

\section{Case report}

A 30-year-old woman presented recurrent epigastralgia treated by proton-pump inhibitor by the gastroenterologist. However after two months, the patient has suffered from an extended chest pain at rest during $40 \mathrm{~min}$ which radiated to left arm, neck and lower jaw. She has no medical history. Furthermore, she had no diabetes mellitus, no arterial hypertension, she had never drink alcohol or smoke and she had no family history of coronary artery disease.

She was admitted to the emergency department. She reported a chronic fatigue and claudications of the upper limbs. The physical 
examination showed a significant asymmetry in pulses and blood pressure between right and left limb. All right pulses were absent with souffle on right subclaviar artery her blood pressure was $80 / 40 \mathrm{mmhg}$ in the right arm and very high in the left arm. The 12 lead electrocardiogram showed sinus tachycardia at $130 \mathrm{bpm}$ and diffuse repolarization abnormalities, ST-segment depression of $2-5 \mathrm{~mm}$ in anterior, septal, apical and lateral derivations, and T-wave inversion in lateral derivations. As the diagnosis of non ST elevation myocardial infarction was made, the patient was referred to the cardiological department. Coronary angiography (Figure 1) revealed a severe stenosis $(70-90 \%), 16-20 \mathrm{~mm}$ of length of the left main coronary artery. There were no lesions in the other coronary arteries. The 2-dimensional transthoracic echocardiography showed an impaired left systolic function, regional wall-motion abnormalities , with a left ejection fraction of 0.35 ,high filling pressure, secondary pulmonary hypertension in addition to a moderate mitral regurgitation ,a moderate aortic regurgitation, and a good right systolic function.
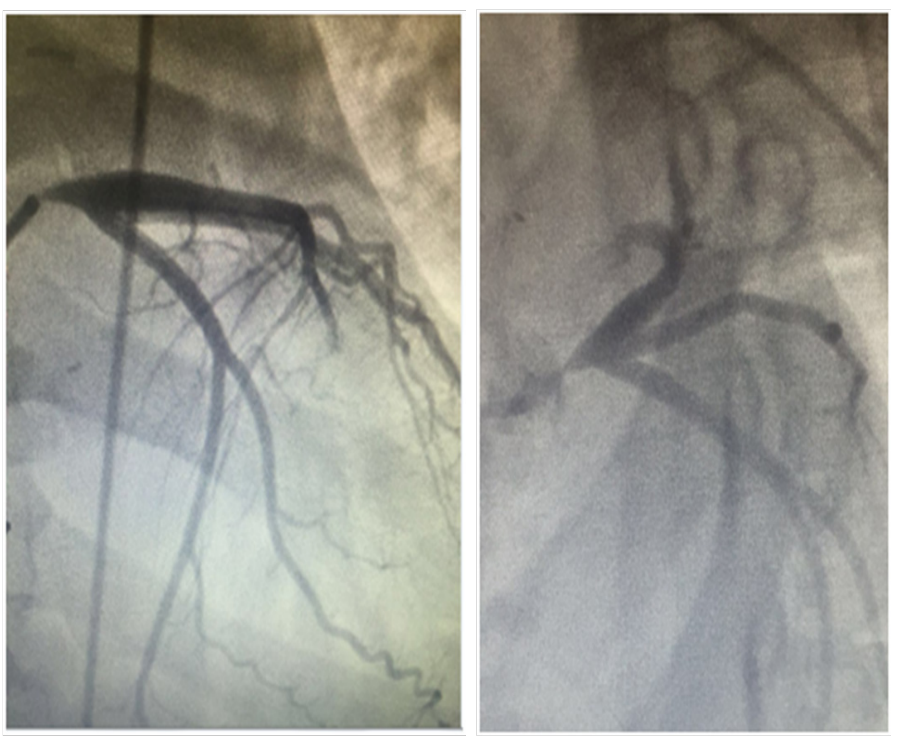

Figure I Coronary angiography: Left main coronary severe stenosis.

Laboratory tests showed a rise of troponin (1.11microgram/1), leukocyte count $\left(12400 / \mathrm{mm}^{3}\right)$, erythrocyte sedimentation rate $(108 \mathrm{~mm} / 1 \mathrm{st}$ hour) and CRP $(68 \mathrm{mg} / \mathrm{dl})$, Kidney and liver function were normal. Lipid profile, coagulation profile and serum fibrinogen were normal. Results for syphilis and HIV were negative. Immunofluorescence antibody test was negative. Other immunological markers were negative (anti-DNA, anticardiolipin, anti B2 Glycoprotein 1, lupus anticoagulant, perinuclear antineutrophil cytoplasmic antibody).

This case has been discussed in a meeting between cardiologists and internists and on the basis of the clinical and imaging findings, Takayasu disease has been retained on ACR criteria. The clinical course was marked by the occurrence of cardiogenic shock complicated by heart arrest. The patient was referred to intensive care. Spontaneous circulation was restored after 16minutes of cardiopulmonary resuscitation. Coronary artery bypass surgery was performed in emergency using the right mammary artery supplying the left anterior descending artery; the right mammary artery was pathologic with a bad blood flow. Given the diagnosis of TA, an etiologic treatment based on corticosteroids was added with a very good response. The patient was given a loading dose of Aspirin, Clopidogrel, Enoxaparine .The pharmacological therapy included Furosemide, converting enzyme inhibitors. B-blockers were introduced secondly after improvement of heart failure. After surgery, no event was reported. The patient was discharged and continued medical treatment, Methotrexate was added as a corticosteroid sparing treatment.

At day 20 after discharge, the patient experienced further episodes of chest pain she was readmitted for acute coronary syndrome coronary angiography showed that the bridge was no functional. Thus, percutaneous coronary angioplasty of the left main coronary artery was performed with implantation of a drug-eluting stent. No other events were reported, the follow up is about four months until now.

\section{Discussion}

In our patient, primary systemic large-vessel vasculitis with a coronary involvement resulted in an acute MI. This case was particular because Takayasu disease was initiated by coronary involvement with a severe presentation, which remains a rare condition. TA should be considered in young women presenting with acute coronary syndrome without a history of atherosclerosis. It should be investigated and treated rapidly, because it can be life threatening. The diagnosis of TA was established according to the American College of Rheumatology. These criteria are:

i. Onset at age under 40years

ii. Decreased brachial artery pulse

iii. Greater than $10 \mathrm{mmHg}$ difference in blood pressure between arms iv. A bruit over the arteries

\section{v. Aorta and arterographic evidence of narrowing}

vi. Occlusion of the entire aorta and primary branches or large arteries in the proximal upper or lower extremities.

The presence of three or more of these criteria is required for the diagnosis. Cardiac involvement is seen in around $22 \%$ of cases and occurs usually later during the disease course. ${ }^{1}$ Coronary involvement in TA is not an exceptional phenomenon. Coronary artery involvement is detected in approximately 10 to $30 \%$ of the cases with TA. ${ }^{2}$

Almost all coronary lesions seem to be ostial or proximal, it was the case of our patient. It exposes patients to severe complications like extensive myocardial infarction or sudden death. ${ }^{3}$ It can be divided into 3 distinct morphologic types: stenosis or occlusion of the coronary Ostia, diffuse or focal coronary arteritis, and coronary aneurysm formation. The majority of the lesions cause luminal narrowing, which lead to occlusion. In contrast to Kawasaki disease, coronary aneurysms in TA are extremely rare. ${ }^{4}$

Narrowing of coronary arteries develops mainly because of extension of the inflammatory processes of proliferation of the intima, and owing to contraction of the fibrotic media and adventitia from the ascending aorta. Accelerated atherosclerosis caused by vascular inflammation may be another explanation of coronary lesions. ${ }^{5,6}$

Doppler ultrasonography, CT and MRI are important tools in diagnosis, but there is no specific imaging technique or serum biomarker. Although conventional angiography is the standard imaging technique in TA. ${ }^{7}$ Recent studies demonstrated that 18 F-FDG 
PET/CT can be helpful in assessment of disease activity before treatment as well as to monitor therapeutic effect or to detect relapse of the disease despite the therapy.

There is no consensus in coronary management in TA. Generally, it requires revascularization procedures with medical treatment (steroids and immunosuppressive agents). Cytotoxic drugs are mandatory to the suppression of inflammatory processes, before surgical procedures. Remission may occur in $40-60 \%$ of patients with TA. ${ }^{9}$

Revascularization difficulties and graft failure are significant problems on postoperative follow-up. That was the case of our patient. A drug-eluting stent may be an optional treatment for left main coronary arterystenosis in TA, because of its immunosuppressive effects in the inflamed arterial walls. ${ }^{10}$ What we learned in the follow up of our patient, is the importance of proper therapy especially inflammation control and medical surveillance, because of the frequency of restenosis and relapses.

\section{Acknowledgements}

None.

\section{Conflict of interest}

The author declares no conflict of interest.

\section{References}

1. Ahmadi-Simab K, Hellmich B, Holl-Ulrich K, et al. Acute coronary syndrome in Takayasu arteritis without elevation of acute phase parameters. Rheumatology. 2007;46(3):554-555.
2. Rav-Acha M Plot L, Peled N, Amital H. Coronary involvement in Takayasu's arteritis. Autoimmun Rev. 2007;6(8):566-571.

3. Soto ME, Meléndez-Ramírez G, Kimura-Hayama E, et al. Coronary $\mathrm{CT}$ angiography in Takayasu arteritis. JACC Cardiovasc Imaging. 2011;4(9):958-966.

4. Ouali S KS, Ben Fradj F, Gribaa R, et al. Takayasu arteritis with coronary aneurysms causing acute myocardial infarction in a young man. Tex Heart Inst J. 2011;38(2):183-186.

5. Matsubara O, Kuwata T, Nemoto T, et al. Coronary artery lesions in Takayasu arteritis: Pathological considerations. Heart and Vessels.1992;7(1):26-31.

6. Seyahi E, Ugurlu S, Cumali R, et al. Atherosclerosis in Takayasu arteritis. Ann Rheum Dis. 2006;65(9):1202-1207.

7. Matsunaga N, Hayashi K, Sakamoto I, et al. Takayasu arteritis protean radiologic manifestations and diagnosis. Radiographics. 1997;17(3):579-594.

8. Chrapko BE, Chrapko M, Nocun A, et al. Role of 18F-FDG PET/CT in the diagnosis of inflammatory and infectious vascular disease. $\mathrm{Nucl} \mathrm{Med}$ Rev Cent East Eur. 2016;19(1):28-36.

9. Giordano JM. Surgical treatment of Takayasu's arteritis. Int J Cardiol. 2000;75(1):123-128.

10. Furukawa Y, Tamura T, Toma M, et al. Sirolimus-eluting stent for instent restenosis of left main coronary artery in takayasu arteritis. Circ $J$. $2005 ; 69(6): 752-755$. 